\title{
Evaluation of Teaching Performance in the Virtual Teaching-Learning Environment, from the Perspective of the Students of the Professional School of Mechanical Engineering
}

\author{
https://doi.org/10.3991/ijet.v16i15.23091 \\ Omar Chamorro-Atalaya ${ }^{1(\varpi)}$, Guillermo Morales-Romero ${ }^{2}$, Nicéforo Trinidad-Loli ${ }^{2}$, \\ Beatriz Caycho-Salas ${ }^{2}$, Sofía Gamarra-Mendoza ${ }^{3}$, César León-Velarde ${ }^{4}$ \\ ${ }^{1}$ National Technological University of Lima Sur, Lima, Peru \\ ${ }^{2}$ Enrique Guzman y Valle National University of Education, Lima, Peru \\ ${ }^{3}$ Saint Ignatius of Loyola University, Lima, Peru \\ ${ }^{4}$ Technological University of Peru, Lima, Peru \\ ochamorro@untels.edu.pe
}

\begin{abstract}
The objective of this article is to evaluate the effect that virtual teaching learning generates in the evaluation of teaching performance, from the perspective of the students, of the professional mechanical engineering school. During the development of the research, it has been determined that the planning, communication and overall performance factors of the teaching performance have experienced a positive variation of $63.64 \%$, increasing by $3.8 \%$, when moving from the face-to-face environment to the virtual teaching-learning environment. While the didactic strategies, organization and subject mastery factors have experienced a positive variation of $59.09 \%$, this increase represents $1.92 \%$. Although a positive effect has been generated on teacher performance, it has been determined that, of the 6 factors, it is the Communication factor which has presented the greatest negative variation, being of the total of 22 teachers, 11 who have decreased their qualification.
\end{abstract}

Keywords-Teaching performance, virtual teaching-learning, mechanical engineering students

\section{Introduction}

Currently, the evaluation of teaching performance, in the public university, is a constant concern, due to the need to increase the quality levels of teaching and in general of all activities carried out in the university environment. In [1], it is pointed out that the university teacher is one of those responsible for stimulating and motivating in students the knowledge of the discipline he teaches and the competencies that are necessary for development in the labor field.

In [2], the author points out that the achievement of academic quality constitutes an intrinsic element and it is the responsibility of universities to judge the quality of their 
processes and products. In the same line of opinion in [3] the author points out that the performance of the university teacher is a factor that is directly associated with the quality of education, which is why it is necessary to monitor it permanently.

In [4], the author points out that the evaluation of teacher performance is a process that should be oriented fundamentally to the estimation of the level of teaching quality, in order to progressively contribute to its improvement. Also in [5], the author points out that teacher performance is the axis that mobilizes the training process within the formal educational system; Therefore, it is necessary to evaluate and analyze it from day to day in a concrete and permanent way.

However, in [6], it is indicated that we are currently witnessing a scenario such that it is not possible to sustain the comprehensive training of students only with the transfer of content, since there is so much information that has made the teacher's performance in the classroom is increasingly relevant.

In this regard in [7], the author highlights that despite the pedagogical and formative changes that the teacher develops in class, they are not valued and recognized by the students; This is where it is necessary to evaluate performance in order to identify the factors that do not allow a meaningful assessment of teaching activity. For this reason, in [8], the author points out that the teaching performance is considered as the balance between the fulfillment of the assigned pedagogical tasks and the result of the educational work; which is reflected in the capacities achieved by the students; For this reason, they are the ones who must establish the degree of evaluation of the teaching performance, in the assigned academic activities.

However, in the context of the health emergency, in [9], it is pointed out that Covid-19 has become a pandemic that has modified the daily life of human beings, and one case of these is university education. For this reason, in [10], it is pointed out that educating in times of pandemic, with totally virtual classes, represents a challenge for teachers and students; Although the teachers were prepared in a theoretical way in the use of virtual tools, in most cases it was only in some virtual resources.

In [11], it is indicated that virtual teaching has been intensively implementing a chain of digital teaching strategies and methodologies; however, few teachers have managed to reach an adequate level in the way of using digital tools; which makes its evaluation necessary in this context. Taking into consideration, as indicated in [12], that professional engineering careers, due to their curricular nature, imply the use of equipment, devices or measuring instruments, to achieve the achievement of the competencies of each subject that makes up the curriculum. studies, in this sense it is relevant to know the teaching performance, in the search for students to achieve the competences of the subject he teaches.

In this sense, it is presented to describe through a comparative analysis the effect that the teaching performance generates, when virtual teaching is implemented in the professional school of mechanical engineering, in a Public University of Peru; for which each teacher will specify their evolution in each of the indicators, from the student's perspective. Finally, the degree of correlation between the analyzed indicators will be determined; in order to statistically validate its association. 


\section{Investigation methodology}

\subsection{Research level}

The research level is descriptive-correlational; descriptive because it is intended to show the evolution of teaching performance in face-to-face teaching-learning (2019II) and virtual teaching-learning (2020-I). And it is correlational because it is intended to statistically identify the degree or level of association of the specific factors (planning, communication, didactic strategies, communication, domain of the subject and organization of the class session) with the global factor of teacher performance, based on the hypothesis that there is a relationship between them. The figure 1 shows the relationship established between the indicators.

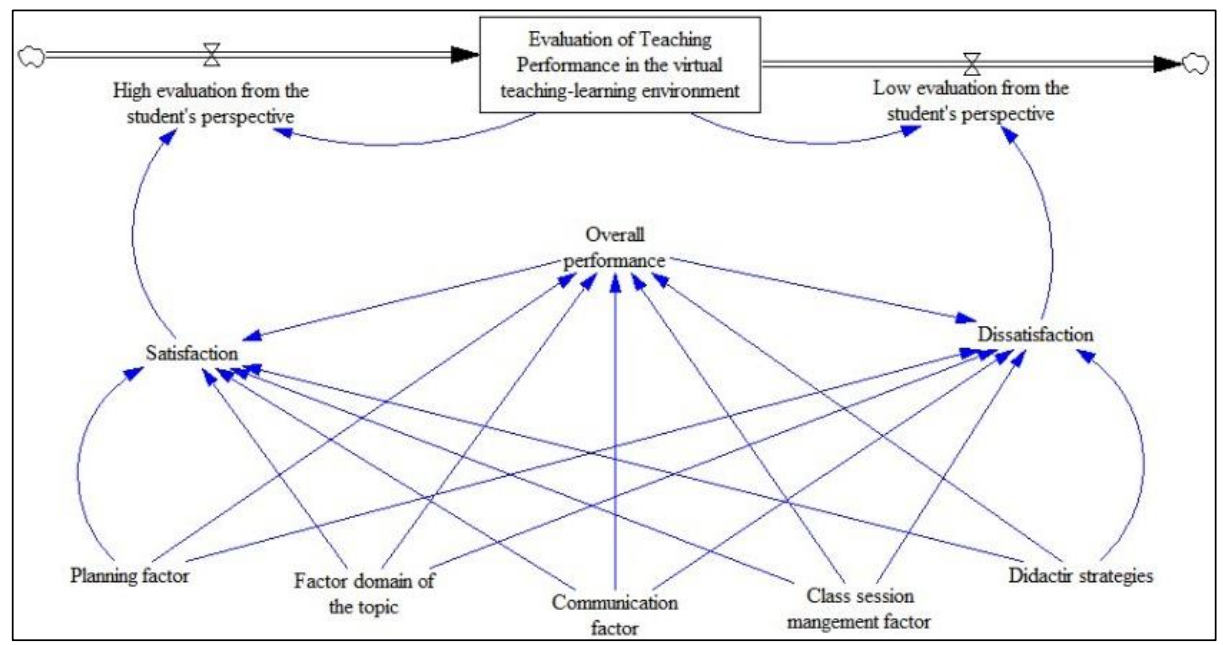

Fig. 1. Model of the relationship between evaluation and teacher performance indicators

\subsection{Study unit}

The population is made up of teachers assigned to the professional mechanical engineering school, these being a total of 22 , in order to have a better precision of the findings or results obtained is that the study unit will be composed of all teachers. Although the study evaluates the 22 teachers of the professional school of mechanical engineering, this evaluation is carried out through the perspective of 870 students of the professional school of mechanical engineering.

\subsection{Data collection technique and instrument}

The data collection technique used in this research is the survey technique; which is composed of six factors, these being: planning factor, didactic strategies factor, 
communication factor, class administration factor, subject domain factor and general evaluation factor.

\subsection{Validation of results of the data collection instrument}

This test will be carried out by means of Cronbach's alpha with SPSS software, the results reveal, according to [13] that there is a high reliability of the data collected of 0.904 , in the 2020-I semester and 0.899 in the 2019-II semester.

\section{Research Results}

\subsection{Comparative analysis of teacher performance factors}

In figure 2 observed that, with regard to the planning factors of the class sessions, communication in the class session and overall performance, 63.64\% (14 teachers) have experienced a positive variation, while $36.36 \%$ ( 8 teachers) have experienced a negative variation from the student's perspective. Likewise, the findings show a slight increase of $3.8 \%$, in the virtual teaching-learning environment. It is important to specify that the evaluations were entered through a vigesimal scale, in the range 0-20.

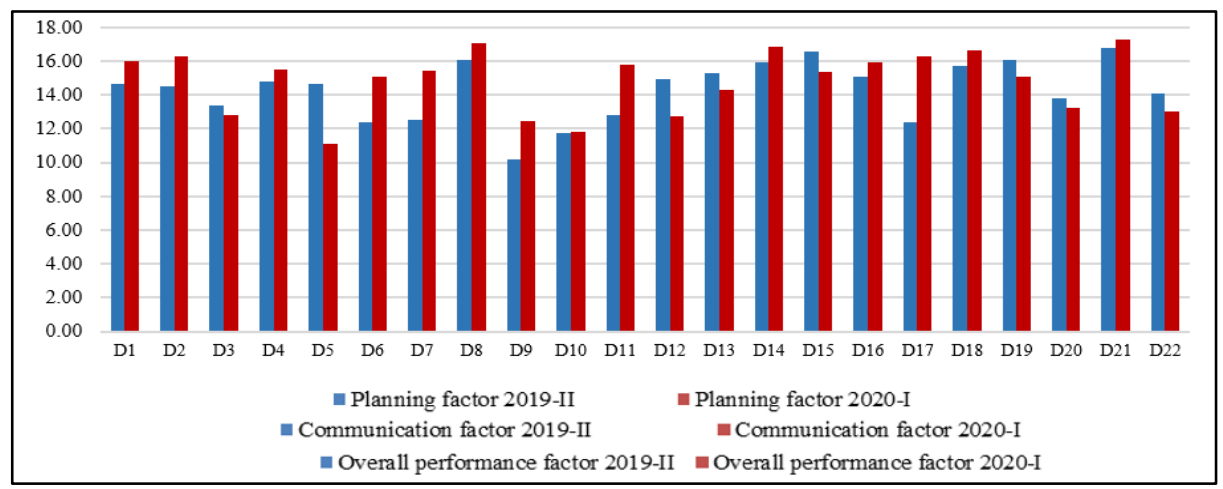

Fig. 2. Variation of the class planning, communication and overall performance

In figure 3 observed that, with respect to the factors didactic strategies, organization of the class session and mastery of the class topic, $59.09 \%$ (13 teachers) have experienced a positive variation, while $40.91 \%$ ( 9 teachers) have experienced a negative variation from the student's perspective. Likewise, the findings show a slight increase of $1.92 \%$, in the virtual teaching-learning environment. 


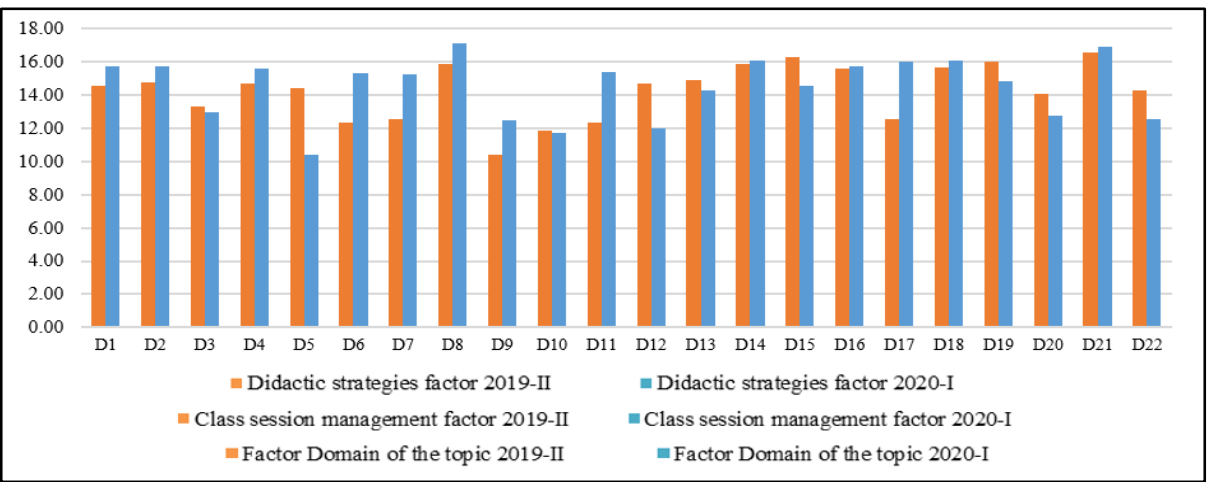

Fig. 3. Variation of the didactic strategies, class session management and domain of the topic

It is important to specify that as part of the findings obtained in the research, it was determined that, of the six factors in the analysis of teacher performance, the Communication factor is the one that showed the highest number of teachers (11) who decreased their performance; Figure 4 shows what has been described.

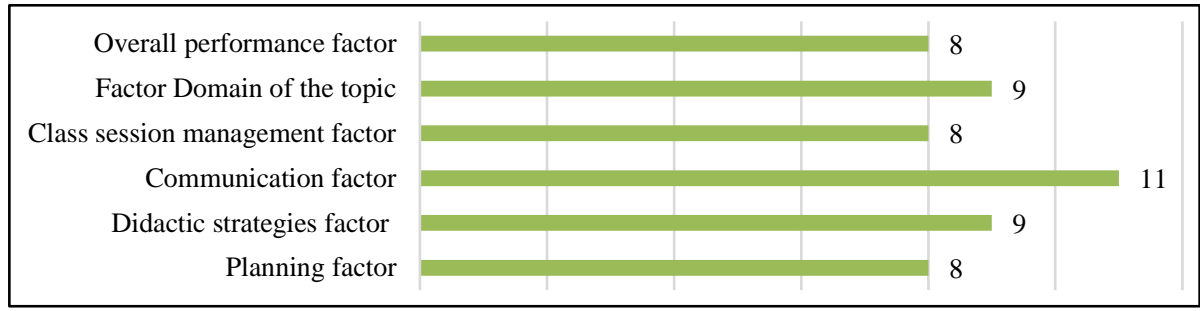

Fig. 4. Number of teachers who have decreased their performance for each factor

\subsection{Identification of the level or degree of correlation between the factors of teacher performance}

By means of the following test, the relationship between the indicators is statistically corroborated, likewise, table 1 , shows that for all cases the Pearson correlation coefficient is higher than 0.972 , this means that the degree or level of association is very high and significant between the specific factors and the global factor of teacher performance.

Figure 5 shows the modeling of the relationship of the factors under study, by means of the Vensim software; As can be seen as the rating of the specific factors increases, the overall performance will also show an increase, which will ultimately be reflected in the teacher performance evaluation variable (blue growing line). 
Table 1. Correlation of overall performance with specific factors

\begin{tabular}{|c|c|c|}
\hline \multicolumn{2}{|c|}{ Sig. $($ bilateral $)=0.00$} & Overall performance factor \\
\hline Planning factor & Correlation of Pearson & 0.977 \\
\hline Didactic strategies factor & Correlation of Pearson & 0.983 \\
\hline Communication factor & Correlation of Pearson & 0.976 \\
\hline Class session Management & Correlation of Pearson & 0.972 \\
\hline Domain of the topic factor & Correlation of Pearson & 0.977 \\
\hline
\end{tabular}

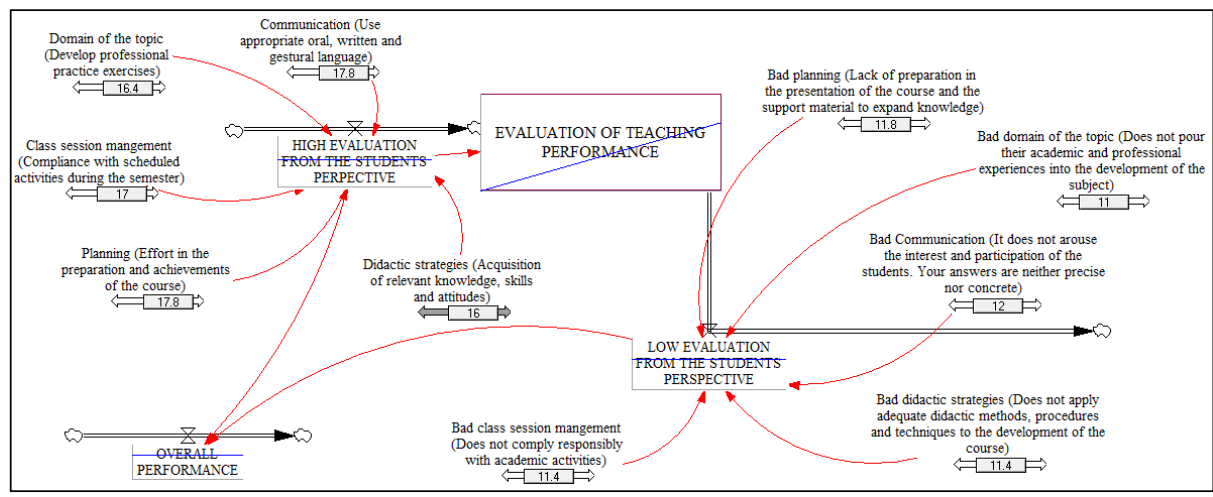

Fig. 5. Representation of the relationship between teacher performance factors

\section{Discussion of results}

Despite the nature of the mechanical engineering career, which implies the use of equipment, devices or measuring instruments, to achieve the achievement of the competencies of each subject that makes up its study plan; According to the perception of mechanical engineering students, of the factors rated at 22 teachers, it has been determined that the factors planning of class sessions, communication in the class session and overall performance of teacher performance, have experienced a positive variation $63.64 \%$; while the factors didactic strategies, organization of the class session and mastery of the class topic, have experienced a positive variation of $59.09 \%$, when moving from the face-to-face teaching-learning environment to the virtual one.

This can be explained, due to the fact that many teachers have used various teaching strategies, such as simulation software and tools used for various calculations; It can be pointed out that the more visual the learning is made, the greater the volume of content that will be processed and incorporated in the form of knowledge. In this way, better retention is also achieved and an increase in the student's security in relation to the solidity of the knowledge that he is acquiring [14].

Although a positive effect has been generated, in teaching performance, it has been determined that, of the 6 factors, it is the Communication factor which has presented the greatest negative variation, from the perception of the students, being of the total of 22 teachers, 11 of them who have lowered their rating. 
It is important to indicate that the communication of the teacher to the student is directly related to the effectiveness that is generated by promoting a favorable environment for learning, this leads to the teacher being able to awaken interest for the participation of students through opinions, questions, discussions, teamwork or other actions; Likewise, it is related to the ability to answer questions and doubts with precision, using an adequate oral, written and gestural language.

Given this, in the study of [15], it is pointed out that students highly evaluate teaching performance, when it provides teaching with clear language, both orally and in writing, that is, a quality in the explanation of the knowledge, that make the student understand efficiently, and can put such knowledge into practice.

\section{Conclusions}

In the development of the research, it is concluded that the factors planning of class sessions, communication in the class session and overall performance of teacher performance, have experienced a positive variation of $63.64 \%$ (14 teachers), generating a slight increase of $3.8 \%$, when moving from the classroom environment to the virtual teaching-learning environment. While the factors didactic strategies, organization of the class session and mastery of the class topic, have also experienced a positive variation of $59.09 \%$ (13 teachers), this increase represents $1.92 \%$ in the virtual teachinglearning environment. Although a positive effect has been generated, in teaching performance, it has been determined that, of the 6 factors, it is the Communication factor which has presented the greatest negative variation, from the perception of the students, being of the total of 22 teachers, 11 of them who have lowered their rating.

Regarding the communication factor, it is recommended to incorporate didactic materials that promote reflection, critical analysis and the elaboration of relationships between what they already know and what they have recently learned, this learning method is constructivist, which must to go hand in hand with the teaching-learning feedback process, which involves exchanges related to questions and answers on the topics discussed, as it helps to verify whether the contents have been learned correctly; In addition, the teacher must emphasize positive points of the activities carried out or attitudes of the students, solving concerns and formulating suggestions, in order to promote and foster a climate of trust and a construction of critical thinking that promotes the development of knowledge.

\section{$6 \quad$ References}

[1] Fernandes, D., Sotolongo, M. and Martinez, C. (2016). "The Evaluation of performance by competences: Perceptions of Teachers and Students in Higher Education", University Formation Journal, vol. 9, no. 5, pp. 15-24.

[2] Rizo, H. (2016). "University Teacher Evaluation. An Institutional Vision," IberoAmerican Journal of Education, vol. 6, no. 4, pp. 112-120. 
[3] De Vincenzi, A. (2017). "Institutional evaluation and improvement of educational quality among private universities in Argentina," Ibero-American Journal of Higher Education, vol. 4, no. 9, pp. 76-94.

[4] Escribano, E. (2018). "Teacher performance as a factor associated with educational quality in Latin America," Education Journal, vol. 42, no. 2, pp. 242-251, 2018.

[5] Tejedor, F. (2017). "Evaluation of teaching performance," Ibero-American Journal of Educational Evaluation, vol. 5, no. 1, pp. 318-329.

[6] Bahati, B., Fors, U., Hansen, P., Nouri J. and Mukama, E. (2019). "Measuring Learner Satisfaction with Formative e-Assessment Strategies," International Journal of Emerging Technologies in Learning, vol. 14, no. 7, pp. 246-247. https://doi.org/10.3991/ijet. $\underline{\mathrm{v} 14 \mathrm{i} 07.9120}$

[7] Naranjo, A. (2019). "The importance of soft skills for teaching in the current context," Journal of Academic Thought of the University UNIACC, vol. 2, no. 1, pp. 82-93.

[8] Hortiguela, D., Assín, V., Delgado V. and Abella, V. (2017). "Analysis of the importance of university teaching academic evaluation and recognition criteria as indicators of educational quality in Spain," High School Journal, vol. 46, no. 181, pp. 75-87.

[9] Castro, M., Paz, M. and Cela, E. (2020). "Learning to teach in times of the Covid-19 pandemic: our experience in a public university in Argentina," Digital Journal of Research in University Teaching, vol. 14, no. 2, pp. 32-41.

[10] Canaza-Choque, F.A. (2020). "Higher education in the global quarantine: disruptions and transitions," Digital Journal of Research in University Teaching, vol. 14, no. 2, pp. 1-10.

[11] Acosta, C., Ortega, D. and Díaz, Y. (2020). "Face-to-face education with virtual mediation: an experience from Honduras in times of Covid-19," Digital Journal of Research in University Teaching, vol. 14, no. 2, pp. 32-41.

[12] Dimas, M., Torres A. and Castillo, J. (2017). "Towards the institutional improvement of the academic bodies in the Faculty of Mechanical and Electrical Engineering of the Autonomous University of Nuevo Leon, Mexico," Electronic Journal Educare, vol. 16, no. 3, pp. 181-202.

[13] Rodríguez-Rodríguez J. and Reguant-Álvarez, M. (2019). "Calculate the reliability of a questionnaire or scale using the SPSS: Cronbach's alpha coefficient," REIRE Revista d'Innovació i Recerca en Educació, vol. 13, no. 2, pp. 1-13. https://doi.org/10.1344/reire $\underline{2020.13 .230048}$

[14] Rossado-Espinoza, V. P., Cárdenas-Salas, D. E., Cabrera-Lau, A., \& Coronel, L. (2021). "Virtual Reality and BIM Methodology as Teaching-Learning Improvement Tools for Sanitary Engineering Courses," International Journal of Emerging Technologies in Learning, vol. 16, no. 6, pp. 20-39. https://doi.org/10.3991/ijet.v16i06.13535

[15] Vlachopoulos, D. (2021). "Quality Teaching in Online Higher Education: The Perspectives of 250 Online Tutors on Technology and Pedagogy," International Journal of Emerging Technologies in Learning, vol. 16, no. 6, pp. 40-56. https://doi.org/10.3991/ijet.v $\underline{16 \mathrm{i} 06.20173}$

\section{Authors}

Omar Chamorro Atalaya, Electronic engineer, Renacyt-Concytec researcher, university professor in the associate category at the National Technological University of Lima Sur, Lima, Peru, ochamorro@untels.edu.pe 
Guillermo Morales Romero, Nicéforo Trinidad Loli and Beatriz Caycho Salas - Teachers at the Enrique Guzman y Valle National University of Education, Lima, Peru

Sofia Gamarra Mendoza, Teacher at the Saint Ignatius of Loyola University, Lima, Peru

César León Velarde, Teacher at the Saint Ignatius of Loyola University, Lima, Peru

Article submitted 2021-04-03. Resubmitted 2021-05-11. Final acceptance 2021-05-12. Final version published as submitted by the authors. 